\title{
Interpreting Non-Amish Perceptions of the Old Order Amish Using Cultural Relativism and Human Rights Frameworks
}

\author{
Kristin Park \\ Professor \\ Department of Sociology and Criminal Justice Studies \\ Westminster College \\ New Wilmington, PA
}

\begin{abstract}
Relatively little is known about how ordinary non-Amish citizens interact with and perceive their Old Order Amish neighbors. This study used interpretive and semi-inductive approaches with indepth interviews to describe and analyze interactions and perceptions of non-Amish research participants. Sixteen subjects were identified from purposive, snowball and theoretical sampling in a region near a sizeable, very tradition-minded Old Order settlement. All participants engaged in secondary relationships, while several individuals had intimate and enduring relationships with a small number of Amish individuals and families. While most participants perceived their Amish acquaintances and friends as honest, hard-working, caring and community-minded, some expressed negative views about racial and ethnic prejudice, rejection of safety devices, hygiene, sanitation and treatment of animals and an overly-restrictive culture. While no definitive conclusions were reached, negative perceptions were analyzed with attention to the preferred stance of cultural relativism for cross-cultural evaluation, while more universal human and animal rights considerations were also articulated.
\end{abstract}

\section{Keywords}

Pluralism; Cultural relativism; Ethical relativism; Human rights; Andy Weaver Amish; Friesen and Friesen (1996); Social constructionism; Qualitative methods

\section{Acknowledgements}

This research was supported by a Hoon Faculty Development Award from Westminster College for the spring semester, 2017. Many thanks to Carol Morrow for her excellent transcription of interviews, and to my research participants for generously sharing their time and thoughts. Thanks also to JAPAS editor Dr. Cory Anderson and the anonymous reviewers for insightful suggestions.

Address correspondence to: Kristin Park, Professor of Sociology, Dept. of Sociology and Criminal Justice Studies, Westminster College, New Wilmington, PA 16172; kpark@westminster.edu 


\section{Introduction}

The contemporary United States is often described as a pluralist environment in which racial, ethnic, religious, and cultural groups maintain distinctive identities, cultural forms, and institutional structures. Such an environment serves subgroups by preserving their cultural boundaries and integrity (Moodian 2013), while such groups, to varying extents, also assimilate through adopting dominant American values, norms, and institutional participation. Cultural pluralism describes the existence of multiple cultural systems within a common economic and political system, while structural pluralism goes further to also refer to individuals' regular participation in segregated institutions such as schools, businesses, and churches (Marger 1997). Persistent subcultures such as the Amish practice both forms of pluralism within an environment offering Constitutional protections of many of their religiously-derived practices.

In evaluating distinctive cultural practices within a pluralist context, social scientists and, ideally, citizens, strive to avoid ethnocentrism, a perspective that evaluates others' cultural elements from their own standpoint, and thus usually as inferior. An opposing perspective, cultural relativism, is often the preferred stance for cultural study and assessment. A more complete discussion of cultural relativism follows this introduction.

While debates about cultural relativism and its limits often center on "exotic" practices such as polygamy, arranged marriage, or female genital cutting, this perspective also applies to analyzing non-Amish evaluations of the Old Order Amish as a distinctive subculture. Culturally relativist analysis is appropriately applied to a society where members' choices are directed by faith, tradition, and a communal orientation, in contrast to non-Amish emphases on efficiency, innovation, and individualism. As will be discussed, at times intercultural tensions arise when Amish practices conflict with dominant, or at least government, standards for safety, health, or human or animal welfare.

This paper describes non-Amish experiences with, and perceptions of, Amish culture in a region that includes a sizeable settlement. Research participants' concerns about Amish attitudes and practices are then evaluated in light of recommended criteria for rejecting cultural relativism and adopting more absolute standards for cultural assessment. In sum, I offer arguments, without definitive conclusions, on whether participant concerns refer to defensible beliefs and practices within the context of cultural relativism, or whether the same elements lie outside of its endorsed acceptance and are worthy of criticism. Especially as new Amish settlements arise around the country and more Amish make a living in ways that require non-Amish interaction, issues of cross-cultural understanding and cultural relativism's endorsement of tolerance become more important.

This paper offers both descriptive and analytical contributions to current Amish scholarship. Descriptively, relatively little is known about the experiences with, and views of, non-Amish citizens toward their Amish community members (Anderson 2017a; Kraybill 2015). 
In particular, this research adds valuable qualitative data and its interpretation to existing knowledge. In addition, little research has been conducted about this particular Amish settlement. Analytically, the paper examines non-Amish attitudes using a distinctive lens and extends applications of cultural relativism to a distinctive North American subgroup.

\section{Literature Review}

\section{Cultural Relativism: Definitions, Evolution, and Controversies}

Cultural relativism (CR) is one of cultural anthropology's overriding concepts, developed in the early and mid-20 ${ }^{\text {th }}$ century in connection with fieldwork methodologies (Hanson 2013) and rejection of $19^{\text {th }}$ century evolutionism (Hatch 1983). Clyde Kluckhohn (1939) described CR as "probably the most meaningful contribution which anthropological studies have made to general knowledge” (p. 342). In a general sense, CR opposes ethnocentrism, a stance by which one comprehends and appraises the beliefs, values and practices of another culture using the standards of one's own, as also influenced by personal relationships and experiences (Hanson 2013). CR begins with the reality of cultural diversity and goes on to reject the concept of objective, absolute, and universal ethics, instead advocating tolerance toward the varied cultural elements of human societies (Rachels 1993).

Cultural relativism refers to and offers criteria for knowledge, morality, and methodology. In its epistemological form, the perspective argues that human knowledge is conditioned by the cultural context within which it is generated. Moral or ethical relativism, the primary concern in this paper, maintains that cultural context determines judgments about what is good, evil, normative, and deviant (Hanson 2013). Ethical relativism warns against Western standards being divorced of historical context and adopted as universal principles, and promotes open-mindedness and individual freedom (Hatch 1997). Finally, methodological relativism (Brown 2008; Hatch 1983), in which observers suspend judgment until completing a careful description of the context, also informs cross-cultural study, though comprehension does not require acceptance of cultural elements. Cultural relativism is opposed by proponents of absolute truths, including adherents of Catholicism, fundamentalist Protestantism, and political conservatism, who fear that this stance leads to hedonism, nihilism, and general disorder (Hanson 2013).

Ethical relativism has been more debated in anthropology in recent decades. As Hatch (1997) argues, "the theory is mistaken to the extent that it denies the very possibility of making moral judgments across cultures or of developing a framework of human rights” (p. 372) Arguments against this strand of CR recognize internal societal conflicts and the existence of broadly shared values and moral codes (Hanson 2013; Rachels 1993), the horrors of the Holocaust (Hatch 1983), increased globalization (Hanson 2013), and debates over international human rights (Tilley 2001). Hatch (1983) argues that one of the perspective’s main proponents, 
Franz Boas, was so concerned about Western harm to developing or indigenous societies that he may have ignored harm within the societies under study.

Importantly, prominent anthropologists conclude that the criteria for cultural tolerance are unclear and satisfactory philosophical justification may be impossible (Hatch 1983). Pragmatically, the alternative to tolerance is intervention, which always brings a cost. Hatch (1983) suggests that appropriate bases for rejection of ethical relativism center around infringements upon freedom, including the threat of force or outright coercion, victimization (especially as subjectively experienced), and attacks upon the security of property. In sum, the well-being of individuals or a people is paramount. Benedict asserts the human right to happiness, while Redfield endorses decency and humaneness (in Hatch 1983). This author sees CR rejection as necessary when universally-recognized human rights are compromised and harm is perpetrated upon living beings and the physical environment that sustains them. Recent study has focused on empirical discovery of moral absolutes that exist as scientific generalizations generated from systematic data analysis (Hatch 1983).

When studying the Amish, it is important to consider the issue of collective versus individual rights. The United Nations' 1948 Universal Declaration of Human Rights does not specifically protect group rights, and special commissions have been established to address this issue. Particular concerns for minority and indigenous peoples have included the right to difference, to culturally-congruent child-rearing, to self-determination, and to control over resources on traditional lands (Messer 1997; Universal Declaration on the Rights of Indigenous Peoples). The occasional need to adjudicate between claims of cultural group rights and individual rights is often done on a case-by-case basis. Messer (1997) notes that traits under consideration are examined in terms of whether they are truly required for cultural identity or continuity, or instead represent historical artifacts or the interests of a particular faction. Thus, the diversity and competing interests within collectivities are acknowledged. Critics of collective rights argue that, in the words of one scholar, "needless proliferation of human rights ... risks devaluing the very idea of human rights and thus subtly weakening all human rights” (Donnelly, in Messer 1997, 304)

Before turning to the design and findings of the current study, it is helpful to briefly examine existing scholarship on non-Amish views toward Old Order Amish communities.

\section{Attitudes toward the Old Order Amish}

Friesen and Friesen (1996) argue that the romanticized portrayal of the Amish in tourist publications is a form of ethnocentrism by which the Amish are seen not as people but rather, via “poetic and mythological renderings,” as “prototypes of a country fantasy” (p. 52) juxtaposed against mainstream failings. Many casual observers highlight the religious devotion, hard work, simplicity, and integration with the natural world of the Amish lifestyle. The authors claim that most observers are unable to view the Amish from an objective, balanced, culturally relativist 
perspective. Importantly, few are able to understand Amish embeddedness in a "comprehensive" community that imposes sociological and psychic costs of discipline, obedience, and conformity. While idealistic portrayals may also be encouraged by the selective reporting of the Amish themselves, they make meaningful intercultural interaction and cross-cultural learning more difficult by denying the full humanity of Amish individuals.

In a similar vein, Weaver- Zercher (2001) discusses how $20^{\text {th }}$ century Americans, and particularly writers, filmmakers, and tourist operators, have constructed the Amish for their own purposes: "to mark boundaries, express fears, support causes and, in many cases, make a profit" (p. 5). The ensuing narratives portrayed the Amish as sanctified "saving remnants" and demythologized "fallen saints." In their "saving remnant" incarnations, Amish values and behaviors critique non-Amish individualism and materialism. When cast as "fallen saints," the Amish are, more objectively, equated with the "rest of us" or, more critically or vindictively, exaggerated in their human failings.

McGuigan and Scholl (2007) administered survey questions to a convenience sample in a small town near a significant Old Order Amish settlement. The authors interpreted perceptions of the Amish in light of social categorization theory and the contact hypothesis. Their findings indicated that most respondents lacked any significant contact with the Amish and scored low on a knowledge index about the religious group. Respondents with deep rather than superficial contact with the Amish held more positive attitudes (showed less bias) toward the religious group. Examples of positive attitudes included agreement with these questions: "There are plenty of Amish people who are very bright, creative, innovative, flexible and adaptable" and "I would like having an Amish family for neighbors.”

Other studies have produced findings derived from very targeted samples. Examining the motivations of seekers exploring plain Anabaptist traditions, Anderson (2016) identified the dominant appeals of religious seriousness, strong community, and modesty among respondents to his web-based convenience sample.

Byers and Crider (2002) and Byers (2008) discussed motivations for Amish victimization, drawing on interviews with perpetrators of anti-Amish hate crimes (such crimes are known as "claping") and situating their findings within routine activities theory. In keeping with theoretical predictions, offenders were motivated and perceived and encountered both suitable targets and absent protective guardians. Expressed reasons for hate crimes included boredom, perceived absence of consequences, and social acceptance of claping. In addition, Byers (2008) identified two dominant "techniques of neutralization” used by perpetrators: "denial of the victim" and "denial of injury," both designed to create psychological and social distance from their targets. With "denial of the victim" offenders highlighted the inferiority of the Amish, as seen in their perceived lack of intelligence, poor hygiene, and hypocrisy. With "denial of injury," the suffering caused by their crimes was minimized, being characterized as teenage mischief and fun. 


\section{Research Context}

This study was conducted in the vicinity of a small town situated near a sizeable Amish settlement located in the surrounding and neighboring counties. The settlement is in Pennsylvania and falls into the Andy Weaver classification, as conceptualized by Petrovich (2017). Approximately 2,200 non-Amish residents live in the town, with an additional Amish population of about 2,400 individuals in 19 church districts in the surrounding counties. Slightly different statistics from the most recent Amish Directory list 550 families within a total population of around 2,089. The town also houses a college with about 1,250 primarily undergraduate students. The Amish have lived in this region since the 1840s. Members of the settlement combine farming with significant employment in woodworking industries as well as construction and a range of small businesses serving Amish and non-Amish customers, including furniture shops, greenhouses, produce shops, small grocery stories, a quilt shop, and tack and harness shops. In keeping with the Andy Weaver classification, and as verified by this author's understanding of the local Ordnung, the settlement's use of modern technology, and the evaluation of an expert Amish scholar (Kraybill 2009), the settlement falls strongly on the tradition-minded end of a tradition-change continuum. There is minimal Amish-themed tourism in the region, although Amish goods are available in some local non-Amish shops, and a local businesswoman operates a small tour company taking tourists to selected Amish businesses.

\section{Theoretical Perspective}

The research follows a semi-inductive approach and uses a social constructionist theoretical perspective (Charmaz 2014). Social constructionism attempts to discover the meanings that members of social groups attach to their lives, and to understand how these meanings derive from interaction and affect group members' behavior. The goal is the discovery of "grounded theory" that is faithful to the data (Charmaz 2014; Glaser and Strauss 1967).

Using a semi-inductive approach, the study was guided by broad research questions asking participants how they interacted with the Amish over time, if they have felt or experienced any boundaries, what they would tell an unfamiliar person about the Amish, and how they perceived historic and contemporary relations between the Amish and English communities. I used a brief, general interview guide whose content shifted during and after the interviews based on what participants found meaningful and important about the topic. Thus, there was a continuous interplay between literature review, data collection, and data analysis. Initial data collection was followed by a return to the literature to deepen knowledge of emerging analyses, such as boundary maintenance by the Amish and cultural relativism, and then more focused data collection based on discovered themes. In sum, in the grounded theory approach, data collection, transcription, analysis, and literature consultation occur throughout the research process and via interplay with each other. 


\section{Research Design}

\section{Sampling and Research Methods}

Rather than striving for representative sampling whose results generalize to a population, this research used a combination of purposive, snowball, and theoretical sampling. A total of 16 individuals were interviewed. I used purposive sampling when I initially approached individuals who I believed had, for example, extended or distinctive experiences with the Amish or who volunteered to participate. Snowball sampling was used when, after each interview, many participants referred additional subjects, both non-Amish and Amish, whom they believed fit criteria that I put forth, i.e. long-term residence in the region but little Amish contact. Thus, snowball sampling interfaced with theoretical sampling, which selected individuals who defined and elaborated "the properties, boundaries and relevance" of emerging categories in the data (Charmaz 2014: 345). Finally, I sought diversity along the lines of sex, age, educational attainment, occupation, level of religiosity, level of broader community involvement, and degree of Amish interaction, including possession of varied roles involving the Amish community (e.g. driver, repairman, and tour operator).

I chose to recruit individuals with long-term residence in the area (15 years or more) so as to allow time for the development of significant Amish contact. I placed a classified ad in the local newspaper to try to recruit long-term residents with minimal Amish contact. This effort produced one participant who misread the ad and indeed had significant contact with that local community. Participants were assigned pseudonyms to ensure confidentiality. In addition, as I was mindful of the tight-knit small town and Amish settlement contexts, I shared potentially identifiable descriptions and quotations in the final paper with their speakers to gain their permission for the degree of detail and specificity that I preferred but with which they might have been uncomfortable. Based on their feedback, I modified my reporting in a couple of cases. See Table 1 for a profile of interview participants.

The research was approved by my college's Institutional Review Board. Face-to-face interviews were conducted in individual homes, workplaces and in the private room of a local restaurant. Based on early participant requests, the interview guide and informed consent form were distributed to all subjects before the interviews; participants were told the guide was flexible and emergent. Interviews lasted between 21 minutes and 1 hour and 51 minutes, with a median of 44 minutes. With permission, 15 interviews were digitally recorded and transcribed, some by a research assistant and some by me. At his request, I took handwritten notes on one interview. The interview format often felt like an informal conversation. I was always touched when participants had assembled their Amish "mementos" or documents that they had collected through their work or leisure contacts. Such mementos included handwritten letters from Amish women requesting sewing machine repairs, an Amish-made birdhouse, lunch boxes painted by an "English" artist with Amish scenes, a book of Amish wisdom, examples of ornate wedding reminder cards, and a thank you note for gifts given to local Amish schoolchildren. 


\section{Table 1: Profile of Research Participants}

\begin{tabular}{|l|l|l|l|}
\hline Sex & Age range & Occupation & $\begin{array}{l}\text { Yers of residence } \\
\text { in region }\end{array}$ \\
\hline M & $80 \mathrm{~s}$ & Retired / College professor & 46 \\
\hline F & Unknown; elderly & $\begin{array}{l}\text { Retired / Homemaker / Volunteer work: Church } \\
\text { leadership and elderly issues }\end{array}$ & 43.5 \\
\hline M & $50 \mathrm{~s}$ & Education administrator & 23 \\
\hline F & $50 \mathrm{~s}$ & Administrative assistant & 14.5 \\
\hline F & $70 \mathrm{~s}$ & Retired / Substitute teacher / Homemaker & 50 \\
\hline M & $80 \mathrm{~s}$ & Retired businessman & 82 \\
\hline F & $50 \mathrm{~s}$ & Education supervisor & 30 \\
\hline M & $50 \mathrm{~s}$ & Financial consultant & 53 \\
\hline F & $50 \mathrm{~s}$ & Businesswoman; Tourist industry & 51 \\
\hline F & $80 \mathrm{~s}$ & Retired / Education and counseling & 21 \\
\hline F & $50 \mathrm{~s}$ & Sales and service to Amish businesses & 52 \\
\hline F & $70 \mathrm{~s}$ & Retired / Small business supervisor & 28 \\
\hline M & $90 \mathrm{~s}$ & Retired / College professor & 65 \\
\hline M & $60 \mathrm{~s}$ & City employee and self-employed repairman & 34 \\
\hline F & $60 \mathrm{~s}$ & Administrative assistant & 32 \\
\hline F & $50 \mathrm{~s}$ & College director & 54 \\
\hline
\end{tabular}

Summary statistics: 10 females, 6 males - Age range: 51 to 94, median $=63$ - Length of residence in region: 14.5 to 82 years, median is about 45 years

\section{Data Analysis}

Data were analyzed using hand-coding that occurred in two stages. During the first reading of the data, open coding identified broad abstract themes. During the second stage of axial coding, initial themes were elaborated or connected so as to identify the key concepts that built the emerging analysis. Additional literature review was conducted to better understand these concepts. Subsequent interview guides and processes focused questions more intentionally around these concepts while deleting or rewording questions that did not produce meaningful data (Neuman 2011; Strauss 1987).

\section{Findings}

\section{Non-Amish and Amish Interactions}

See the appendix for a complete list of categories and examples of participant interactions with members of the local settlement. While there is significant variation in the extent of my sample's interactions, several individuals have had intimate and enduring interactions with Amish individuals and families over many years. In most cases, these friendships were with from one to four Amish individuals or couples and sometimes their families, but in one case, involving business and leisure, the interactions were with "about 15" 
families. Note that the requirement of at least 15 years of "community" residence selects for more, and perhaps more intimate, interactions.

At the more superficial end of the continuum, many individuals had business transactions at Amish-owned produce stands, greenhouses, a quilt shop, and grocery stores; had hired Amish craftspeople, construction workers, or repairmen; and had served as a, usually unpaid, driver for the Amish. These more superficial relationships constitute what sociologists refer to as secondary relationships, which are short-lived, relatively impersonal, and instrumental, in contrast to primary relationships that are enduring, identity-enhancing and expressive in nature (Cooley 1909). In a few cases, the participant's occupation involved ongoing exchanges with the Amish; these participants also tended to have more in-depth friendships that both derived from, and broadened and deepened, these instrumental exchanges.

These more extensive, enduring, and intimate interactions included primary relationships that participants classified as friendships. Their experiences included a variety of individual and family leisure activities as well as gift exchanges of both tangible and intangible goods, including, in a few cases, discussions about faith. Several participants (and their spouses) had attended Amish weddings and funerals. One participant and his wife drove in the funeral procession since an Amish relative was unable to fulfill that task.

In reviewing the data, one is struck by the ambiguity of the boundaries that define such interactions. When questioned, some participants indicated that they had never sensed any boundaries, while they were certainly aware that they existed as social norms and that their Amish friends must be attuned to them. For example, one woman expressed that the many getwell cards that she received from the Amish community while she was hospitalized might have pushed interaction limits, though a large segment of the community sent these cards. Another woman explained her close friendship with an Amish woman as possibly due to the Amish woman's being childless, without the usual concerns about how "English" contact might affect her children. One might suspect that Amish sharing of religious beliefs and interpretations would represent unacceptable boundary-crossing, but one participant had engaged with an Amish man in discussions about life after death, while another had participated in Bible reading with an Amish family and had interviewed members of the local settlement about their interpretations of the Nickel Mines shootings for a church project. Research participants also self-censored by staying away from certain topics or questions that they suspected might cause discomfort. In short, Amish-English boundaries were more fluid than expected, though I suspect those engaging in boundary-crossing were outliers within the larger Amish settlement.

In addition to business intersections and physical proximity, shared roles and identities between participants and their Amish contacts also facilitated friendships. These roles and identities included being born into or having assumed parenthood within large families (as normed against contemporary U.S. family size), embeddedness in rural life, a devout Christian identity, and commitment to a pacifist way of life. Constance bonded with an Amish family who 
were challenged by serious illness of two of their children, noting that since her family "had passed through this," she shared information about medicines and transported the family to distant doctors' appointments. The Amish family offered her money for transportation, which she turned down. She and the family entered into an exchange agreement instead, rooted in faith:

And they saw the sign inside my car that said 'war is not the answer.' So we immediately had a bond of something, call it a faith agreement, I don't know, but they knew that my stance was not necessarily the traditional stance of the `English’ people. And so we worked out a wonderful relationship in which they would give me eggs, or they would bake cookies, for my grandchildren or for the family [...] they came up with the most wonderful treats, because I can’t take their money [...] And so we found ourselves on common ground in that way because they understand that in community you give what you have, and then you take from others. So this was a nice match, for us.

Constant concluded that their bond was further strengthened by her strong devotion to children, and she was extremely blessed to discover that medicines that had not worked for her family member successfully treated this family’s son.

In conclusion, there is a paradox in the Amish mandate of separation from outsiders, as grounded in a history of persecution, and the increasing encroachment of modernity, yet the presence of strong primary relationships with non-Amish community members. This level of discovered intimacy may be somewhat exceptional. Many participants noted that getting to know their Amish friends took time and trust; it was not easily accomplished. In addition, as members of the settlement have moved away from full-time farming toward business ownership and construction work, they have been required to have more "English" interaction. Several individuals noted a dramatic change in recent decades with more informal and friendly interactions around town, compared to the greater Amish reserve of the past. The prevailing consensus was that "it's hard to get in, but once word gets around that you are okay and can be trusted,” you can have cordial exchanges, if not develop deep friendships.

\section{Positive Cultural Evaluations}

The "saving remnant” and "fallen saint” frames discussed earlier are useful broad categorizations of participant perceptions in this research. However, it should be emphasized that most participants expressed strongly positive views of Amish culture. These constructions are the dominant narrative that emerges from the research. I summarize and briefly exemplify some of these appraisals below, as the focus of this paper is interpretation of negative cultural evaluations.

Many participants emphasized that the Amish are just like us, humans with all of their virtues and failings. Francis' conclusions were echoed by many: "some of whom are expert craftsmen and some not, some of whom are super-pious and some that push the envelope and they are careful whose watching before they do certain things.” These comments challenge 
Friesen and Friesens' (1996) conclusion that idealization of the Amish, as socialized through tourist publications, denies them their humanity.

Many participants admired the Amish as, for the most part, honest, hard-working, willing to live within material and Christian limits, and living with a slower, more mindful pace of life. Ann noted that "I think there's something to be said for that kind of simplistic lifestyle that doesn't burden you with being overly committed to things." Gregory noted that he would like his children to spend a week living on an Amish farm to experience thrift, hard work, and lack of technology; Ellen said "I wish we could take some of how they live and bring it to our culture."

Another recurring theme was respect for the Amish sense of community, as seen in generous assistance to other Amish and to non-Amish when tragedy strikes. Lydia noted, “They're here for their neighbors and each other [...] Nobody's ever really alone, as an Amish person.” Elizabeth told a story that "absolutely touched my heart," whereby her neighbor's small horse farm burned down, and the next day, Amish men appeared to clear away the debris and, within three days, build a new barn. She concluded "I've never seen anything like it [...] this is how the Amish are [...] from then on in, my total respect for them.”

Finally, a perhaps unexpected perception shared by several was that the Amish are fun and funny people. Contradicting a public impression of the faith as somber, participants enjoyed the joke-telling and teasing they found in family gatherings while playing games or doing activities like sled-riding or visiting the zoo.

Participants were asked about their view of community relations, between Amish and non-Amish, during the time they had lived in the region. Most perceived such relations as harmonious; some saw no divide but rather all residents as part of one unified community. Many members of both communities collect funds and food for each other's' families in need. Many non-Amish attend and support the yearly auction that provides medical funds for the Amish community. Road condition issues, related to steel wheel ruts from buggies and manure deposits by horses, are sometimes raised but have not been truly problematic. While the Amish community lives by the principle of non-conformity, in this case the distance between their lives and those of their racially and religiously-similar neighbors promotes an easier coexistence than seen, for example, by Hedberg's (2016) Old Colony Mennonites, who distanced themselves from the perceived pathologies of their Guaraní neighbors. The next section highlights and evaluates cultural concerns expressed by non-Amish residents.

\section{Negative Cultural Evaluations}

Several individuals expressed concerns about Amish cultural elements that they had witnessed. It is these negative evaluations that represent the data for the subsequent cultural relativism analysis. My intention is not to judge my participants, as many of these concerns have been noted by other scholars and observers, but rather to evaluate their critiques using a new lens. An important distinction to remember is that, in some cases, the critique might not refer to 
Amish culture per se but rather to particular individuals who are acting outside of prescribed norms.

\section{Prejudice against minority groups}

One concern centered on expressed prejudice against members of ethnic and minority groups, particularly Polish-Americans and African-Americans. Francis noted "The dirtiest, raunchiest Polish joke I ever heard was from an Amish person,” and Thomas recounted

And another thing that happens with men [...] they love to joke around [...] and they are very into racial jokes [...] and my assumption is that [...] I don't know how they don't feel like second class citizens $[\ldots]$ so to feel like they are not a low part of society they do this, since they are only laborers and cannot advance beyond that.

Another participant, who later asked not to be quoted, had referred to Amish use of dated, non-politically correct language in referring to blacks, Native Americans, and women. This individual referred to the smaller Amish worldview and lack of modern communication technologies as preserving these mindsets. A personal acquaintance shared with me that she no longer brings along her multiracial son when she shops at a local Amish greenhouse as he is uncomfortable being stared at by the family on the premises.

\section{Rejection of safety devices}

Even participants with overall positive appraisals of the Amish sometimes expressed grave concern about the community's rejection of safety devices that would protect its own members, specifically smoke detectors and cell phones for medical emergencies. While the Amish settlement has experienced several recent fires, Norman recounted an incident that destroyed a local home and killed the mother and two children. In his capacity as an official within the local governance structure, he solicited local charities to donate 300 smoke alarms and battery donations and approached the head Amish bishop with this offering:

And I said I would like to give you these and you can distribute them among the churches, and (the bishop said) [...] oh, no, we can't accept those. We can't take them. I said why can't you take them. He said that's just how it is, it is God's will, and if he thinks there should be a fire [...] and that jolted me. I was rather angry. It's God's will, I mean this is their basic thing [...] A tragedy.

Ken noted that "you hear the horror stories where the whole family dies because they don't believe in smoke detectors. Now that's crazy."

Despite her strong friendship with and respect and love for members of an Amish family over many years, Constance expressed concern about their rejection of telephones for medical emergencies. This family had a special needs son and enlisted Constance to be the intermediary with the public school where he attended. When, "fairly often," there were emergencies with the child, the school would call Constance on her cell phone or landline to pick him up. She noted: 
But you know the thing I never asked, because it's not mine to ask, where in the Bible does it say that you can't have [...] why can't they have one of these for emergencies? If I hadn't been able to come, they had no backup plan.

And that's a gap. For all my admiration of them, and I hope you sense it is very sincere, on the other hand, what is so awful [...] I understand their reasoning about the telephone lines connecting people [...] I don't approve of it but I understand it [...] but if it were just an emergency for [the Amish children] ... not I'm calling my girlfriend to see if she got the pizzas ready! (laughs)

Laura also expressed concern about how even when a wife is nine months pregnant, a phone will not be brought into the home. She concluded "and we think [...] that's just safety and logic and you need to have that, but they must look at us with horns and a tail. (laughs)"

\section{Hygiene and sanitation}

Several participants raised concerns about Amish hygiene and sanitation, as these issues affected their own and other non-Amish lives as well. In reference to Amish food production, Ken noted, "I'm not so much for eating that stuff. (laughs) [...] It just seems to me that, as clean as they are, they can’t really be super sanitary, and that bothers me.” He also referred to observing a site where chickens were being canned "with feathers and stuff everywhere" and to seeing drawers of canned meat in homes that he had visited. While Martha acknowledged that most of the houses are very clean, she avoided most Amish food, including the legendary Amish donuts, due to the "kerosene taste" and flies.

Ann referred to her involvement on a committee for planning a park system in the town. A veiled concern was expressed about the need for public restrooms with no one available to provide the more thorough cleaning of them that Amish use would require. Norman described a former business that had two public bathrooms which they ended up locking because "the Dutch didn't take care of them.”

More serious criticisms were raised by Martha, who lives in a formerly Amish home and has had continuous problems with "five, six or seven” Amish families living in her neighborhood. These problems have turned her youthful enchantment with the Amish into strong disillusionment. While acknowledging her concerns might not be generalizable, she framed them in the context of perceived hypocrisy as "(the Amish) are supposed to care about the land and animals.” She mentioned upon moving in that she and her husband found two huge dumping sites "for junk and trash" and an outhouse "full of garbage and other kinds of stuff" on the property. Citing additional concerns including alleged stolen items and a lack of reciprocity in exchanges of goods and aid, Martha differed from several other participants who put forth the Amish as positive role models. Instead, she described these instances as "teaching moments" for her children on how not to treat others in your environment. 


\section{Treatment of animals}

A more serious concern was the sanitary butchering of, and treatment of, animals. Martha cited what she saw as many instances of improper disposal of animals, such as cows and horses, after they die ("it will just be thrown over the hill, and then as it rots and decays, the smell in the wind”). She told a story of an Amish-owned dog who became pregnant and about the time they knew she would be giving birth "we heard a couple of gun shots, so we went over [...] and we had this little Amish girl carrying over the last puppy and said, 'Here Daddy, here's the last one,' and then you hear a shot. So they killed the puppies instead of dealing with having them."

Martha also cited a story where she returned home to find "a huge bath of blood" in front of her sidewalk. She panicked that something had happened to her husband. What apparently happened was that Amish neighbors had slit the throat of a pig they were slaughtering, who then got away and ran to their house and “they finished it off right there. But didn't leave a note, didn't do anything [...] it was just a huge, big puddle. I didn't know if someone was murdered there or what.” Martha also mentioned discovering shotgun shells in her grass and then noticing dead fish in her pond: “just bizarre things like that, you know, I mean it’s crazy.” In dealing with ongoing issues, she and her husband have contacted the game commission and the local bishop and set up surveillance cameras on their property.

Nicole also cited concerns about Amish treatment of dogs and horses in the context of comparisons with "English" culture; she noted that "their animals aren't treated quite like ours are.” She specifically discussed dogs being continuously tied up (“which we generally wouldn’t do") and that other Amish-owned dogs roam free and "act like they're going to attack you, the more aggressive ones." She observed that the horses are thought of as "work animals" so "they will discipline them [...] a few times I've seen this with a whip [...] or just pulling hard back on the reins [...] but it's unnerving for us.” A personal acquaintance who is an accomplished equestrian shared her observations and evaluations of Amish treatment of horses, as well as on the Amish women who drive them:

I'd say in general that Amish treat their work horses, the cold bloods or draft animals, much better than their road horses [that pull buggies]. I generalize, too, that Amish women are the worst in terms of safety and consideration for the road horse. Maybe they simply don't know better - haven't ever been respected enough to be taught —or simply express some of whatever's repressed in them by driving like maniacs. They do. My grandmother, who lived next door, used to fuss about trotting a [buggy] horse downhill. It's terribly hard on their joints and is poor horsemanship overall. The weight of the buggy, even if [the] harness is properly fitting and attached, pushes the horse to go faster and faster, too. I know of one woman, a trainer, who's stopped in front of a buggy after she passed it, and scolded the driver, male or female, saying the horse should see a vet [because] it is so lame and/or is improperly shod. 
The Amish also are their own blacksmiths, or farriers, trimming and shoeing their own horses [because] it is cheaper for them. They don't measure to make sure all four feet are even and they have little to no training other than what is passed down from father to son. The variation, therefore, is enormous. Some Amish love flashy horses and treat them well. I don't mean to denigrate everyone. Like all communities, individual members differ. Overall, however, my experience and what I've heard from family (who know or knew horses) and from other horse-y types is that the Amish do mistreat and abuse their animals, horses included, if not also particularly their buggy horses. (Personal correspondence 2017)

\section{An overly restrictive culture}

Finally, several participants shared their criticisms of the local settlement as overly restrictive of its members. One set of concerns focused on Amish education. The local historical context here is that of a 1950's consolidation that brought rural "English" children to town schools, while the Amish stayed in one-room schools. The local school district continued to staff Amish schools with certified teachers and “contemporary” programming. In 1974, after the Wisconsin vs. Yoder decision, the Amish notified the local school district of their intention to withdraw from the public schools and establish their own parochial schools; this arrangement continues today.

Norman expressed his distress about the current segregation as it has limited Amish opportunity in the context of diminished farming:

(Emphatically)And that's a tragedy that happened to the Amish here [...] and I will speak on that [...] not allowing the students to come to our schools [...] so now several generations of Amish with some manual skills, but mental skills, they are out of touch with so much [...]. A terrible thing [...] and many of my friends in the Amish community think so too.

Norman volunteered that his Amish friends open up to him and reveal that they don't want to be as isolated as they are. Some individuals seek him out for access to communications, like newspapers or radio.

As an individual with enduring contacts with several Amish friends, Thomas described his "transformation [...] let me find the right word [...] development in this area" after originally, upon arrival to the region, "having [the Amish] on a pinnacle.” While expressing that most Amish are "nice people" and admiring the slower pace of life with the non-adoption of modern technologies, Thomas continued: "I'm getting a little more skeptical about the Amish community [...] a little bit about the closed-mindedness of them" and that he sees individuals who feel "stuck.” He lamented that the current bishops will no longer accept "English” textbook or educational magazine donations and that the Amish children "are falling behind, not as educated as they used to be.” Like Norman, Thomas was concerned about how Amish individuals would assimilate into society due to these restrictions. He noted that older Amish who were taught in shared public schools have "thought processes higher up in Bloom's level.” However, Janet indicated that her school district donates outdated books to the local Amish schools, some of 
which are accepted and others not. And Ruth told about a local librarian dropping off old encyclopedias to families, and that local children had learned about Native American cultures in school, including a presentation by a Native American speaker who was approved by the school board.

Laura, with years of extensive business and personal involvement with many Amish families, commented on how their limited education affects Amish awareness of "possibilities and what else is out there." She discussed how the Amish lack of self-sufficiency can feel like an imposition on her and other non-Amish: "they really do kind of push beyond the bounds of [...] social norms. So we as (pause), service providers and friends of the Amish, sometimes have to weigh out or filter what do we really want to be involved in." She referred to Amish dependence on non-Amish for advice about and assistance with business transactions, for borrowing equipment, for accessing transportation, and for arranging mediation for sales communications. In addition, she referred to receiving phone calls that sometimes turn into extended requests because "they're hoping for the greatest success when they go to the phone somewhere.” An example given by Laura and many participants is that the "English' driver for the Amish" role nearly always extended beyond transporting of the originally-intended passengers to include several more individuals added along the route. However, for most, this arrangement was felt to be amusing or slightly annoying rather than truly burdensome. Laura also referred to the cultural prohibition against "being on display" as limiting potential employment, as seen in the preponderance of wholesale over retail Amish businesses and the restriction on Amish women working in establishments like local restaurants or nursing homes. She also believed that more sheltered Amish lacked the self-confidence for "English" interaction that their changing society requires.

Finally, Thomas spoke with great emotion about what he saw as cases of arbitrary decision-making by bishops. He discussed an Amish couple, with whom he and his wife are close friends, who were unable to have biological children and were told by the bishop, with no reason given, that they were unable to adopt a child. Another couple in the district was granted this permission. Thomas felt that this decision has caused severe and enduring psychological depression for his male friend. He described another case where, in his evaluation, an Amish builder was seen as becoming "too wealthy" so was directed into another line of work, with no explanation given.

\section{Summary}

In sum, non-Amish participants critiqued Amish culture around several elements: expressed prejudice against members of ethnic or racial groups; rejection of safety devices, including in their homes; hygiene and sanitation concerns in food production; public restroom use; disposal of trash and dead carcasses; and inhumane treatment of animals. In addition, several participants lamented what they saw as excessive restrictions in educational content, occupational choice, and church decision-making. This restrictiveness was thought to limit 
Amish self-confidence, well-being, and self-sufficiency, should a member choose to not join the church or later assimilate into non-Amish society.

\section{Discussion}

As discussed, ethical relativism - the appropriate form of cultural relativism to frame this paper-denies the existence of objective and universal standards by which to evaluate cultural beliefs, values, and practices. As long as a practice is in accordance with a culture's proclaimed moral codes, observers adopting this perspective must practice tolerance toward their own and others' cultural elements (Rachels 1993). I argue that a culturally relativist stance must be rejected when the physical or mental well-being of humans or other animals is seriously compromised and when significant harm is inflicted upon the physical environment that sustains the existence of living beings.

Regarding human rights, critics of wide-scale, non-reflective endorsements of cultural relativism reference broadly shared values and moral codes across cultures (Hanson 2013; Rachels 1993) and international human rights, while acknowledging that human rights standards are not static, as declarations are historically-situated and subject to ongoing debate (Hernlund and Shell-Duncan 2007; Tilley 2001). Scholars have put forth varying moral criteria to reject a culturally relativist position, including restrictions on freedom (Hatch 1983), restrictions on humaneness (Redfield, in Hatch, 1983), felt victimization (Hatch 1983), and compromised human happiness (Benedict, in Hatch 1983). Challenges exist when individual human rights clash with collective conceptions, while competing interests within communal societies must be acknowledged (Messer 1997).

Regarding the physical environment, there exists close linkages between the environment and the enjoyment of human rights. According to the United Nations' Division of Environmental Law and Conventions, the environment is a pre-requisite for human rights enactment. The right to a safe, clean, sustainable, and healthy environment is a fundamental human right, although this is the subject of debate ("Human Rights and the Environment").

Before offering assessments of Amish practices measured by this position, several caveats must be stated. First, some of these critiques may refer to individual aberrations outside of or contrary to the endorsed values and Ordnung of this particular settlement rather than to established, normative beliefs and practices. Second, participants' critiques are second-hand accounts of local attitudes toward their Amish neighbors, not documented, verified behavior. Third, the sample size, at 16 participants, is modest. Therefore, one must take care in generalizing these findings to the broader settlement and, even less so, to the population of diverse Amish settlements throughout North America. Some of these concerns have been noted, however, in both scholarly and popular treatments of a variety of Amish communities.

Given these caveats, where concerns do seem culturally-referenced, are they unacceptable expressions of ethnocentrism toward Amish culture? Or are these criticisms 
validated, as they derive from more universal standards for human, animal, and environmental rights that highlight well-being and security?

First is the expression of ethnic and racial prejudice by some Amish individuals. To the extent that they exist, how much harm do such attitudes create, for members of the Amish community and for members of the targeted groups? To what extent do these attitudes translate into discriminatory behavior? It is true that this settlement exists within a larger region characterized by considerable racial homogeneity; most residents are white. Thus the opportunities for interaction with members of minority races, and possible resulting discrimination, are minimal, although not absent.

Psychological research confirms the contact hypothesis, which states that prejudice is reduced by contact between members of in-groups and out-groups, especially but not only when facilitating conditions such as perceived equal statuses, cooperation toward shared goals, and institutional support are present (Pettigrew and Tropp 2006; Allport 1979[1954]). As members of the settlement increasingly interact with the larger society as hired laborers and small business owners, and occasionally interact with tourists, the potential for harm is increased. While even unexpressed prejudice causes psychic damage to one who embraces it, the larger concern is acts of discrimination against members of targeted groups who then experience feelings of inferiority that infringe upon their rights to happiness and full societal inclusion. Of course, non-Amish also practice prejudice and discrimination against minority groups, despite the value of equality being institutionalized in anti-discrimination education and laws within the larger American society. Research participants may have higher expectations of the Amish due to the tendency to idealize this community. ${ }^{1}$

Similar considerations arise regarding the Amish treatment of animals; is perceived or criminally-indicted substandard treatment a social problem arising from a problematic collective mindset or are such instances individual aberrations? There are occasional stories in the news media about alleged "puppy mills” and inhumane treatment of horses (for example, “Amish Dog Breeders to Improve Standards, Reputation”; “Amishman Plans Dog Business: Activists Fear Puppy Mill”; "Hot Horses and Amish animal cruelty”). As an agricultural people who view and use animals in primarily practical, economic ways, Amish views are less sentimental than those of many non-Amish who indulge their “companion” animals as family members, even referring to themselves as "pet parents.” In her narrative about leaving the Amish, Garrett (2003) observed that "on an Amish farm animals are viewed more as commodities or pests than pets or natural wonders" (p. 9).

But in reference to the cases presented in this paper, Amish butchering practices are not defensible when they foul the property and living environment of, and cause mental anguish to, neighbors. As such, they infringe on the need for a safe and clean physical environment as a precondition for human well-being. When such concerns were brought to the attention of the local bishop, the behaviors ceased, at least for the time being. Other concerns around perceived 
animal cruelty are justified if they violate established animal welfare laws for living conditions, care, and proper discipline.

In addition to its ethical implications, as noted by Amish scholar Diane Umble (in Williams 2015), the rejection of safety devices by some settlements is also a church-state issue, found especially within more traditional groups and particularly when those groups have migrated to new locales that lack an historic Amish presence. Settlements in Wisconsin, Kentucky, and New York recently have been mired in legal issues of obtaining building permits that require installing smoke and carbon monoxide detectors for new residences (Williams 2015; Belton 2012). Installation of detectors represents a classic case of the First Amendment's guarantee of the free exercise of religion unless the state has a "compelling interest" in restricting that freedom due to concerns such as public health and safety (Evans 1998). When refusal to install such devices violates state building codes, Amish individuals have been fined. In one case, the refusal to pay such fines led the judge to stay the case and transfer it to federal court. In Wisconsin, the Amish received a religious exemption, with subsequent dismissals of their fines and court costs. Additional government responses have included eviction and, sometimes with agreement between Amish and authorities, removal of the detectors after initial inspection. More traditional Amish object to such devices as "modern" instruments that may interfere with divine plans (Belton 2012).

Constitutional issues aside, church members hold deep religious convictions about abiding by God's law rather than human law, and they most certainly do not casually or recklessly ignore safety concerns. The situation is complicated when the well-being and lives of children, who have not taken baptismal vows and thus chosen church membership, are at stake, and especially when parents believe they are acting in the best interests of their children. American culture grants parents considerable autonomy in child-rearing practices, including for diet, activities, and discipline. Societal intervention overrides parental authority, via child protective agencies, only when parental decisions involve abuse or neglect, including medical neglect (Orr and Novotny 2003). One sees comparisons with cases of parents refusing medicallynecessary treatments for their children based on belief in divine intervention. Children can be seen as victimized when their lives are at risk due to rejection of available safety devices, whether such devices are legally mandated or not.

Regarding Amish educational content and practices, Wisconsin vs. Yoder in 1972 affirmed the right of the Amish community to educate children in accordance with cultural values, beliefs, and priorities. Several research participants expressed concerns that the Amish educational curriculum is too limited and provincial, not providing the broader exposure needed by individuals who, increasingly, interact with the "English" world in business transactions or, rarely, choose to leave the faith and assimilate into American society. One sees here participant endorsement of the broader American purpose and promise of education as broadening the mind and offering individual choice and opportunities. Yet, as the local settlement has interacted more with non-Amish society, it is understandable, in the interests of retaining youth and preserving 
cultural integrity, that Amish leaders become more rather than less restrictive in overseeing youth education. Schools, especially at the primary level, are critical socialization agents, teaching not just subject-specific knowledge and skills but also dominant values and ideologies, using pedagogies that reinforce cultural boundaries. The Amish educational system exactly accomplishes these purposes. Indeed, a pluralist environment respects and, with some Constitutional restrictions, facilitates parents' wishes to educate their children within religious and cultural frameworks, as seen in evangelical Christian, Catholic, and Jewish schools, as well as schools operating with alternative pedagogies (e.g. Montessori schools) and home schooling environments.

Finally, participants referred to additional examples of an overly-restrictive culture in terms of consequences for Amish and the non-Amish who work with them. Strict rules were thought to contribute to young people feeling trapped within the culture and to the settlement's compromised autonomy, with significant dependence on the non-Amish due to technological and employment limitations. Yet, English individuals can choose the extent of their assistance, though negotiations can be difficult when actors bring unequal resources to the table. Amish church members surrender to their district's Ordnung, with its requirement to abide by the bishop's recommendations, which becomes binding when ratified by all church members. In addition, in being Amish, one need not require explanations for conferred decisions, which are seen to emanate from a divine source. However, it is ironic that, in attempting to remain traditional within the reality of changing employment, the edict to live separately from the temptations of the world is compromised.

Recall that Thomas expressed dismay about his Amish friends being denied child adoption, perceiving the decision as arbitrary and as causing prolonged and severe depression for the male member of the couple. Denial of a parenting experience could be especially painful in this strongly pronatalist context where such a role signifies achieved adulthood, full social belonging, and high social status. If Amish individuals perceive restrictions as unacceptable, they can migrate to another settlement or leave the faith, while no one would deny the painful and disruptive impact of these paths.

Obviously, there is potential for cultural misunderstanding and conflict when a traditional, deeply religious, and communal culture encounters a modern, secular, and individualistic one. In decision-making, the Amish refer to natural law with its conception of beings with superior powers of understanding and privileged access to truths. These divine representations possess rationales which mortals are unable to understand (Shweder 1990). The conception and professed virtues of cultural relativism are anathema to the Amish, with their Biblical literalism that offers absolute truths and their hierarchical authority structures that require total allegiance. The Amish benefit from a pluralist environment that often protects their religious freedom, or sometimes goes to significant lengths to craft reasonable compromises when state interests are invoked. Given dominant tendencies toward ethnocentrism, non-Amish, and especially those with the power to create and enforce laws, have a responsibility to educate 
themselves about Amish culture. Such cultural awareness would hopefully limit intervention in Amish practices to cases where significant and well-documented compromises to human, animal, and environmental well-being are found.

\section{Limitations of Study and Suggestions for Future Research}

While qualitative research does not aspire to representative sampling, it is important to note sample characteristics that likely influenced my findings. As noted, and by design, I selected for participants with extended residence in the region so they had the opportunity for significant Amish experiences. Follow-up research should examine newer residents whose contacts might be more a matter of personal initiative or circumstance. While the sample does vary in participants' extent and depth of interactions, my efforts to reach more long-term residents with minimal contact, via a newspaper advertisement and directed snowball sampling, were not as successful as I hoped.

In addition, the sample may be biased toward respondents with positive views of, and experiences with, the Amish community. While the tone and extended content of many interviews suggested genuine respect and affection, I have some evidence that those with more muted or negative experiences chose not to be interviewed. These data raise interesting questions about how potential and final participants constructed the interview experience and my research goals, as distinct from the information that I provided when contacting them.

Two individuals whom I approached told me that they felt they were being asked to "inform" on their Amish friends or acquaintances for Ordnung violations or, in one case, to report on "bad behavior" that they had witnessed when, as a teen, they socialized with Amish youth. In the latter case, the participant stated, "I'm not sure if what you need to hear, you want to know." Another woman explained her decision not to ask her husband to participate: "it's like 'ratting' on your friends when you know things that are done, that aren't supposed to be done because they are Amish, and I didn't want to put [my husband] in that position.” She asked for a copy of the interview guide, which I shared, but I did not hear back from her so did not pursue the interview further. Several potential participants did not respond to requests for interviews, although reasons for their nonresponse are unknowable.

Affirming the complementarity of qualitative and quantitative methods, a survey of regional residents could better assess the generalizability of the findings in this study. Recall that in their 2007 study of non-Amish residents from the same geographic area, McGuigan and Scholl found that most respondents lacked any significant contact with the Amish and that positive attitudes were associated with deeper contact. Future research on the Amish might also identify non-Amish views on these and different Amish practices in settings that vary on dimensions such as date of establishment of the settlement and tradition or change-mindedness of the respective Ordnungs. 
Finally, cultural relativism and its competing perspectives provide useful lenses within which to view and evaluate the Amish subculture. Recall that Friesen and Friesen (1996) expressed concern about romanticized depictions of the Amish and argued for culturally relativist and value-free perspectives that situated individuals within an obedient, discipline-bound community, with associated psychic costs. They argued that idealized portrayals deny the humanity of members of this distinctive subculture. This research extends their discussion with its application and critiques of a culturally relativist framework to a specific, tradition-minded settlement. Debates about the merits and limitations of ethical relativism are rich, illuminating and ongoing among anthropologists, philosophers, and other scholars of culture. There is a relative dearth of research applying this perspective to subcultures within pluralist, multicultural societies. Additional case studies of this form, of communities whose members coexist and interact on a daily basis, would extend the discussion in useful ways. Such study might help to further specify appropriate moral criteria for evaluation, to empirically identify moral absolutes across cultures, and to explore tensions between individual and collective rights.

\section{Endnote}

${ }^{1}$ Anderson (2017b), drawing on his knowledge of Amish society, suggested that this perceived prejudice may reflect the Amish interest in difference and tendency to compartmentalize elements in their world. He wondered how the racial jokes entered the culture, such as through auction interactions or encounters with the rural, hunting culture. Perhaps Amish drivers are another entry route. He wondered if individuals really understood the meaning of their comments, and was skeptical that, given the Amish worldview, prejudice translated into discrimination.

\section{Bibliography}

Allport, Gordon. 1979 (1954). The Nature of Prejudice. Cambridge, MA: Perseus Books.

“Amish Dog Breeders Seek to Improve Standards, Reputation.” Retrieved July 3, 2017 (http://amishamerica.com/amish-dog-breeders-seek-to-improve-standards-reputation/)

“Amishman Plans Dog Business: Activists Fear Puppy Mill.” Retrieved July 3, 2017 (http://amishamerica.com/colorado-amishman-plans-dog-business-locals-fear-puppy$\mathrm{mill} /$ )

Anderson, Cory. 2016. "Religious Seekers' Attraction to the Plain Mennonites and Amish.” Review of Religious Research 58(1):125-47. https://doi.org/10.1007/s13644-015-02225

Anderson, Cory. 2017a. "Seventy-Five Years of Amish Studies: 1942 to 2017: A Critical Review of Scholarship Trends (with an Extensive Bibliography.” Journal of Amish and Plain Anabaptist Studies 5(1):1-65. https://doi.org/10.18061/1811/81076 
Anderson, Cory. 2017b. Personal communication, July 28.

Belton, David. 2012. "New York Amish in court over smoke alarms.” Retrieved March 14, 2017 (http://www.bbc.com/news/magazine-18108197).

Brown, M.F. 2008. “Cultural Relativism 2.0.” Current Anthropology 40(3): 363-83. DOI https://doi.org/10.1086/529261

Byers, Bryan. 2008. "Amish Victimization and Offending: A Rural Subculture's Experiences and Responses to Crime and Justice.” Southern Rural Sociology 23(2):226-51.

Byers, Bryan, and Benjamin Crider. 2002. "Hate Crimes against the Amish: A Qualitative Analysis of Bias Motivation Using Routine Activities Theory.” Deviant Behavior 23(2):115-48. https://doi.org/10.1080/016396202753424529

Charmaz, Kathy. 2014. Constructing Grounded Theory. 2nd ed. Sage Publications.

Cooley, Charles Horton. 1909. Social Organization: A Study of the Larger Mind. New York, NY: Charles Scribner's Sons.

Evans, Bette Novit. 1998. "Religious Freedom vs. Compelling State Interests.” Rabbi Myer and Dorothy Kripke Center for the Study of Religion and Society 9(2). Retrieved July 12, 2017 (http://moses.creighton.edu/csrs/news/s98-1.html).

Friesen, Bruce, and John Friesen. 1996. Perceptions of the Amish Way. Dubuque, IA: Kendall/Hunt.

Garrett, Irene, with Rick Farrant. 2003. Crossing Over: One Woman's Escape from Amish Life. San Francisco, CA: Harper.

Glaser, Barney and Anselm Strauss. 1967. The Discovery of Grounded Theory. Chicago, IL: Aldine.

Hanson, F. Allan. 2013. “Cultural Relativism.” Pp. 150-54 in Theory in Social and Cultural Anthropology: An Encyclopedia, edited by R. Jon McGee and Richard L. Warms. Sage Publications. https://doi.org/10.4135/9781452276311.n51

Hatch, Elvin. 1983. Culture and Morality: The Relativity of Values in Anthropology. New York, NY: Columbia University Press.

Hatch, Elvin. 1997. “The Good Side of Relativism.” Journal of Anthropological Research 53(3):371-81. https://doi.org/10.1086/jar.53.3.3630959

Hedberg, Anna Sofia. 2016. "The Dynamics of Boundaries: Obedience and Transgression among Bolivian Old Colony Mennonites." Journal of Amish and Plain Anabaptist Studies 4(2):149-67. https://doi.org/10.18061/1811/79935 
“Hot Horses and Amish Animal Cruelty.” Retrieved July 3, 2017

(http://amishamerica.com/hot-horses-amish-animal-cruelty/)

Kluckhohn, Clyde. 1939. “The Place of Theory in Anthropological Studies.” The Philosophy of Science 6:328-44. https://doi.org/10.1086/286562

Kraybill, Donald. 2009. Personal communication. September 22.

Kraybill, Donald. 2015. Personal communication. May 20.

Marger, Martin. 1997. Race and Ethnic Relations: American and Global Perspectives. 4th ed. Wadsworth.

McGuigan, William, and Carol Scholl. 2007. "The Effect of Contact on Attitudes Toward Old Order Amish.” Journal of Applied Social Psychology 37(11):2642-59. https://doi.org/10.1111/j.1559-1816.2007.00274.x

Messer, Ellen. 1997. "Pluralist Approaches to Human Rights.” Journal of Anthropological Research 53(3):293-317. https://doi.org/10.1086/jar.53.3.3630956

Moodian, Michael A. 2013. “Pluralism.” Pp. 1709-10 in Multicultural America: A Multimedia Encyclopedia, edited by Carlos E. Cortes. Sage Publications. https://doi.org/10.4135/9781452276274.n694

Neuman, W. Laurence. 2011. Social Research Methods: Qualitative and Quantitative Approaches. 7th ed. Allyn \& Bacon.

Orr, Robert and William Novotny. 2003. "Faith-based Decisions: Parents Who Refuse Appropriate Care for their Children.” AMA Journal of Ethics 5(8).

Personal correspondence to author. August 30, 2017.

Petrovich, Christopher. 2017. "More Than Forty Amish Affiliations? Charting the Fault Lines.” Journal of Amish and Plain Anabaptist Studies 5(1):120-42. https://doi.org/10.18061/1811/81072

Pettigrew, Thomas, and Linda. Tropp. 2006. “A Meta-Analytic Test of Intergroup Contact Theory.” Journal of Personality and Social Psychology 90(5):751-83. https://doi.org/10.1037/0022-3514.90.5.751

Rachels, James. 1993. “The Challenge of Cultural Relativism.” Pp. 15-29 in The Elements of Moral Philosophy. 2nd ed. McGraw Hill.

Shweder, Richard. 1990. “Ethical Relativism: Is There a Defensible Version?” Ethos 18(2):205-18. https://doi.org/10.1525/eth.1990.18.2.02a00050 
Strauss, Anselm. 1987. Qualitative Analysis for Social Scientists. New York, NY: Cambridge University Press. https://doi.org/10.1017/CBO9780511557842

Tilley, John J. 2001. “Cultural Relativism.” In Readers’ Guide to the Social Sciences. Retrieved July 7, 2011 (http://www.credoreference.com/entry/rousocial/cultural_relativism).

“Universal Declaration on the Rights of Indigenous Peoples.” Retrieved July 20, 2017 (https://www.un.org/development/desa/indigenouspeoples/declaration-on-the-rights-ofindigenous-peoples.html).

Weaver-Zercher, David. 2001. The Amish in the American Imagination. Baltimore, MD: Johns Hopkins University Press.

Williams, Kevin. 2015. "Increasing Tension over Some Amish Beliefs as Communities Grow.” Retrieved March 14, 2017 (http://america.aljazeera.com/articles/2015/7/7/increasingtensions-over-amish-traditional-practices-as-community-grows.html).

\section{Appendix: Non-Amish Interactions with Local Amish Individuals}

\section{Ceremonial}

Amish wedding attendance (one with 9 or 10 weddings with husband; two with invitations but could not attend)

Amish funeral attendance (several; two invited but could not attend)

Attended birthday party of young Amish boy and family

Invited to and attended Amish Christmas show

Invited to and attended Amish house raising

Amish friends attended participant’s wedding

\section{Family Leisure Activities}

One English and two Amish families together: corn harvesting, canning, making apple butter, making quilts, raising and slaughtering chickens, playing games (Dutch Blitz), doing jigsaw puzzles, taking Amish children to zoo with own family, going fishing with Amish family, sled riding, baseball

Much interaction with neighboring Amish families (including "best friends"; one primary family, but also several others) while growing up: Sled riding, baseball, food sharing, playing Dutch Blitz

Visits and dinners at both Amish and English homes (several participants) (including New Year's Eve, Thanksgiving)

Three trips to adjoining state to visit with relocated Amish family friends

Takes families on her tour route to local restaurant, variety store and local park 


\section{Individual Leisure Activities}

Book conversations about archaeology book with Amish friend

Book loan and conversation about calculus book with Amish friend

Helped Amish friend find books (with participant using Internet)

Doing carpentry with Amish friend

Fishing with Amish family

Gave two young Amish men ride in sports car

Chatting with Amish friend in home

Visiting with elderly Amish step-sisters

Brief interactions with Amish while walking dog

Taking out-of-town and international visitors to meet Amish friends, view Amish farms and stop at Amish businesses (several)

Hosted Amish-themed dinner at church, with Amish food contributions and aid by Amish woman

Overnight vacation with Amish family to explore businesses practices in another Amish settlement

\section{“Gift” exchanges}

Received Amish rugs

Passed on National Geographic magazines to Amish friends

Swap cookies and cards at Christmas with neighboring Amish family

Received many Amish cards, and food for her family, after surgery

Amish neighbor boys cleaned gutters

Set up phone in barn to be used by Amish neighbor

Advertises to help Amish families find homes for puppies

Serves as "phone directory" for local Amish

Donated food to family whose sons drowned (several)

Amish friend burns trash (with identifying labels) and newspapers

Gives plastic bags to Amish friend

Videotaped horse's paces so Amish man could critique its development

Go-between with Amish special needs children in school; arranged meeting of English and Amish mothers of such children

Assistance to local Amish boy with cancer and girl with disability: note, funds, transportation to medical appointments (barter arrangements with eggs, cookies as thanks)

\section{Educational and Religious Activities}

Discussions about Bible, faith and pacifism with Amish (several)

Conversations about Nickel Mines tragedy with Amish friend; brought his insights to church study group on forgiveness

Interviewed Amish for popular book

Wrote religious articles for local newspaper to which Amish sometimes responded 


\section{Business Transactions}

Customer at Amish produce and baked good stands, greenhouses, tack shop, furniture shops, quilt shop, fabric shop, dry goods store, Bent n’ Dent Grocery (many participants). Bought dog, buys flowers, bought small decorative houses

Driver for Amish (usually unpaid; rarely paid for longer trips; often with gift exchange): medical appointments, shopping, eating at restaurant (many participants)

Hiring of Amish: furniture making; carpentry; home and church repairs and remodeling, including window installation and roof repairs and replacement (many participants); house painting; home building; house cleaning; canning; craftsperson to repair musical instrument; craftsperson to repair archaeological artifacts.

Contracted with local Amish to build artifact display cases

Amish girls as occasional babysitters while growing up

Sales and service provided to local Amish business owners

Repair business for sewing machines with significant Amish customers

Education supervisor of Amish "multi-handicapped” children in public schools

Tour operator taking domestic and international visitors to region to local Amish businesses

Purchased Amish property and land when vacant

Bought Amish house that her family restored

Two-way land and property rentals with Amish 